\title{
An Empirical and In Silico Study of the Survival of Dairy Cows in Heterogeneous Population
}

\author{
Gennady G Cherepanov* \\ Institute of Animal Physiology, Biochemistry and Nutrition - Branch of Ernst Federal Scientific Center for Animal Husbandry, Russia
}

Submission: December 17, 2018, Published: December 20, 2018

*Corresponding author: Cherepanov GG, Institute of Animal Physiology, Biochemistry and Nutrition - Branch of Ernst Federal Scientific Center for Animal Husbandry, Borovsk, Russian Federation, Borovsk, Kaluga oblast, Russia.

\begin{abstract}
The data from biomedical studies show that the patterns of mortality in a population considered as a whole may differ significantly from the mortality rates in the constituent subpopulations. An analysis of empirical data reveals heterogeneity in survival parameters in populations of various types of laboratory animals and humans. The aim of this work is to present empirical data and results of in silico study indicating the possible approaches for early forecasting the viability of dairy cows in heterogeneous populations.
\end{abstract}

\section{Introduction}

The data from bio-medical studies show that the patterns of mortality in a population considered as a whole may differ significantly from the mortality rates in the constituent subpopulations. An analysis of empirical data reveals heterogeneity in survival parameters in populations of various types of laboratory animals and humans [1]. In the study of the health status of the public health in radiation lesions, taking into account the heterogeneity of populations allows obtaining more accurate estimates of risk factors [2]. The fact that the revealed consistent patterns have of general biological nature is evidenced by the results of the analysis of empirical data on the age dynamics of productivity and survival in the populations of dairy cattle [3].

Several methodological approaches for early quantifying the viability of cows at the level of group (e.g., bull's daughters), herd or population were described by the author earlier [4]. The aim of this work is to present empirical data and results of in silico study indicating the possible approaches for early forecasting the viability of dairy cows in heterogeneous populations.

\section{Empirical study}

As a material for the study, the records of the age composition of the herds of Black-and-White cows in 16 breeding firms of the Leningrad oblast of Russian Federation in the period 1985-1990 were used, averaged over 5 years to compensate for deviations from stationary state in herds turnover. The dynamics of culling rate of cows from the herd (culling intensity from respective cohort when herd is in stationary state of turnover) in most cases is usually approximated by the Gompertz function $\mathrm{y}_{\mathrm{c}}(\mathrm{t})$

$$
Y_{c}(t)=\Delta S /\left(S^{*} \Delta t\right)=B \exp (c t)
$$

Where; $t$ : is number of the current lactation, $S$ : Is the quantity of cows in cohort, $\Delta \mathrm{S}$ : Is the difference in the number of cows at the previous and current lactation, $\Delta t: 1, B$ and $c$ are constants.

The function, inverse to the culling intensity, characterizes the age decrease of viability. The dynamics of cows leaving the dairy herd over 8-10 lactations in 16 breeding units was approximated by the Gompertz function with an average value of $R^{2}=0.79$.

When analyzing the data obtained, a higher level of variability in the parameter $B$ was noted (the intensity of culling at first lactation), compared with parameter $c$. Previously, certain grounds were obtained for interpreting the reciprocal of $y_{c 1}\left(y_{c}\right.$ at $\left.t=1\right)$, i.e. $B^{-1} e^{-c}$ as an indicator characterizing the viability potential of this group of animals $[4,5]$. In other words, differences in the level of viability formed at the beginning of reproductive period can determine (on the average, in group or population) differences in the length of productive life (LPL) [4].

This pattern will be most clearly expressed if the compared groups or populations have similar values of $c$ in the Gompertz function. This is theoretically possible in a situation if the aging 
rate, characterized by $c$, is determined mainly by stable genetic factors, including the breed features. Since the Leningrad type of Black-and-White breed during period of data registration was a stable population, it can be assumed that this population could have the same value of $c$, and the variations found between the components of this population are due to the heterogeneity of the studied herds in respect to values of the parameter $B$.

As a definite argument in favor of this second interpretation of the variability in parameter $c$, it can be considered the negative relationship between the parameters $B$ and $c$ detected in 16 studied breeding firms $\left(c=0.19-0.45^{*} \mathrm{~B}, \mathrm{R}^{2}=0.69\right.$, $\left.\mathrm{P}<0.001\right)$, i.e. the more $\mathrm{B}$, the less $\mathrm{c}$. This gives grounds for assuming that the herds studied are heterogeneous in terms of survival dynamics, while variations in the values of the parameter $B$ have a significant effect on the values of $\mathrm{c}$ recorded in the studied herds.

\section{Study in silico}

To verify the assumptions made, 4 series of calculations were performed on the Gompertz discrete model implemented in the format Excell MS with a step $\Delta t=1$ to predict survival of cows in four model heterogeneous subpopulations (I-IV) with the same initial number $n$ (1000 cows at the first lactation), each of which consists of four homogeneous groups with different values of the initial number $n$ and parameter $B$, but with the same value of $c$ ( $c$ $=0.1$ ) (Table 1$)$.

Table 1: The structure of four model heterogeneous subpopulations, each of which consists of four homogeneous groups.

\begin{tabular}{|c|c|c|c|c|c|}
\hline \multirow{4}{*}{ I } & $\mathrm{n}$ & 100 & 400 & 300 & 200 \\
\cline { 2 - 6 } & $\mathrm{B}$ & 0,35 & 0,3 & 0,25 & 0,15 \\
\cline { 2 - 6 } & $\mathrm{t}_{\max }$ & 4 & 5 & 7 & 8 \\
\hline \multirow{3}{*}{ II } & $\mathrm{n}$ & 300 & 300 & 300 & 100 \\
\cline { 2 - 6 } & $\mathrm{B}$ & 0,4 & 0,3 & 0,2 & 0,1 \\
\cline { 2 - 6 } & $\mathrm{t}_{\max }$ & 6 & 7 & 8 & 8 \\
\hline \multirow{3}{*}{ III } & $\mathrm{n}$ & 400 & 300 & 200 & 100 \\
\cline { 2 - 6 } & $\mathrm{B}$ & 0,4 & 0,25 & 0,2 & 0,15 \\
\cline { 2 - 6 } & $\mathrm{t}_{\max }$ & 5 & 6 & 8 & \\
\hline \multirow{3}{*}{ IV } & $\mathrm{n}$ & 400 & 300 & 200 & 100 \\
\cline { 2 - 6 } & $\mathrm{B}$ & 0,35 & 0,25 & 0,2 & 0,15 \\
\cline { 2 - 6 } & $\mathrm{t}_{\max }$ & 5 & 7 & 8 & 8 \\
\hline
\end{tabular}

Note: $n$ : Initial size of the homogeneous groups (number of cows at the first lactation), B: Parameter in Gompertz function, $t_{\max }$ : Maximal length of productive life (in lactation numbers).

It is assumed that this model experiment reproduces the main features of the studied situation in which all 16 subpopulations belonging to breeding firms in different regions of Leningrad oblast, consist of several groups homogeneous by parameter $c$, i.e. having the same value of this parameter, but different values of B. In the calculations, the truncated Gompertz distribution was used and as the maximum LPL $\left(\mathrm{t}_{\max }\right)$, the value of $\mathrm{t}$ was taken, at which the number of unrecorded long-lived cows is a negligible small fraction (less than 2-5\%) of the initial number (atthe first lactation). Under this condition, the average LPL (T) is approximately 2 times less than the value of $t_{\max }$ [3]. The dynamics of culling rate in the four model heterogeneous populations were approximated by the Gompertz function with a high coefficient of determination $\left(\mathrm{R}^{2}\right.$ $=0.81-0.92)$; the values of $c$ in variants I-IV varied from 0.079 to 0.113 (in all homogeneous groups in the subpopulations, $c=0.1$ ), and there was a close negative relationship between the values of $B$ and $c$ (Figure 1).

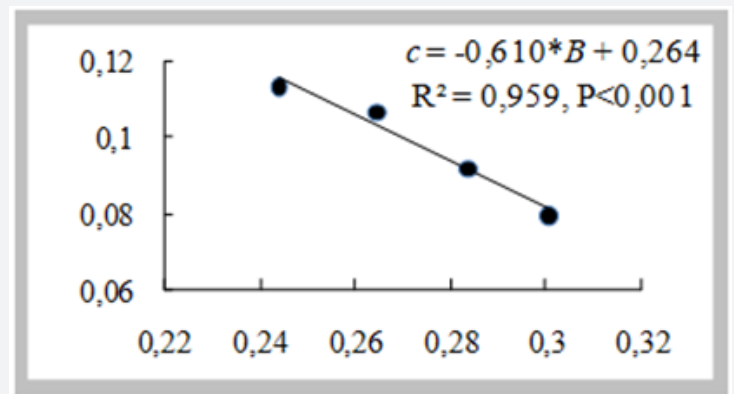

Figure 1:The relationship between parameters $B$ and $c$ in the general model population, consisting of 4 heterogeneous subpopulations (I-IV in table).

The fact that the correlation between $B$ and $c$, detected in the modeling longevity in heterogeneous population, is also established on empirical data for 16 breeding farms, supports the above formulated assumption that the rate of aging of dairy cows, characterized by the value of $\mathrm{c}$ in Gompertz function, is determined mainly by stable genetic factors, including breed features, whereas the observed population variability of LPL depends on the viability potential formed to the beginning of the reproductive period. Earlier, it was shown that this potential can be expressed as the reciprocal of the culling rate at the first lactation [4]. The results of this in silico study confirmed the presence of a negative correlation between the value of B and the LPL in the total set of homogeneous groups that have the same value of $c$ (Figure 2).

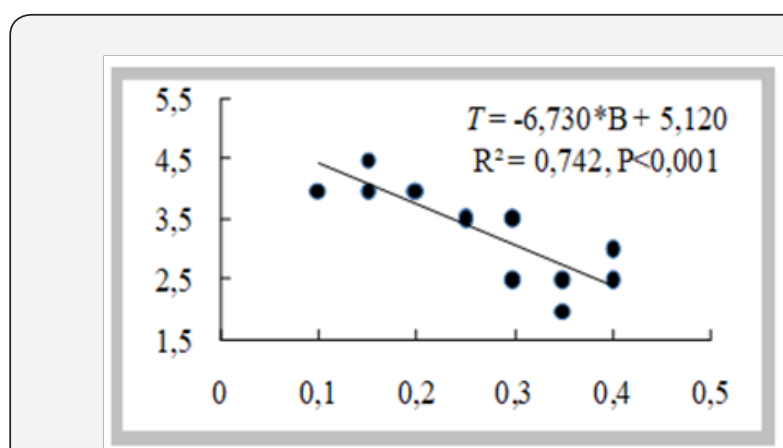

Figure 2:The relationship between the average length of productive life $\mathrm{T}$ and parameter $\mathrm{B}$ in 16 groups with different initial numbers $\mathrm{n}$, but the same value of the parameter $\mathrm{c}$.

The results obtained, and our interpretation of the identified patterns are consistent with the scientific data, indicating that the animal viability is determined not only by genotypic factors, but also by epigenetic modifications, arising in response to endogenous and exogenous effects at the early stages of ontogenesis [6-10]. Since the identified patterns depend not only on the inherited genetic structures, but also on the "history" of events occurring 
during critical periods of development, descendants are born in cows, and groups (subpopulations) with different potential of viability are formed in herds and populations.

\section{Conclusion}

In general, the data obtained suggest that to create optimal type of dairy cows with a balanced ratio of milk productivity and viability, as well as for early prediction of the length of productive life, it is reasonable to create a system of lifelong monitoring of external influences and the physiological status of animals at all stages of ontogenesis, as well as an appropriate data analysis technologies for finding the effective predictive tests. Possible candidates for the role of tests for the prediction of productive longevity should not be search in terms of physiological homeostasis; they are more likely to be found in the area of action of constitutive and epigenetic factors. To extend the length of productive life, in addition to fighting diseases, it is necessary to increase the "initial" value of total resistance, i.e. functional reserves at a young age, with the use of different approaches, including selection, elimination of adverse deviations in the course of embryonic, fetal and postnatal development, as well as the application of technological influences at a young age, contributing to an increase in overall protective reserves.

\section{References}

1. Vaupel JW, Carey JR, Christensen K, Johnson TE, Yashin AI, et al. (1998) Biodemografic trajectories of longevity. Science 280(5365): 855-860.
2. Ivanov RV, Mikhalskii AI, Ivanov VK, Chekin SYu, Maksyutov MA, et al. (2017) On identification of morbidity parameters in a heterogeneous model: the cases of complete and incomplete information. Automation and Remote Control 78(7): 1329-1340.

3. Cherepanov GG, Mikhal'skii AI, Novosel'tseva ZhA (2017) Estimation of survival parameters for components of a heterogeneous population of productive animals: problem analysis, approximate solutions. Problems of Productive Animal Biology 4: 83-97.

4. Cherepanov GG (2018) Prediction of viability of cows: a new look at the old problem. Agri Res \& Tech: Open Access J 14(5): 555931.

5. Cherepanov GG (2014) Substantiation of the concept of the key role of constitutive resistance for the viability and duration of use of highly productive animals. Problems of Productive Animal Biology 4: 5-34.

6. Helfand SL, Inouye SK (2002) Rejuvenating views of the aging process. Nat Rev Genet 3(2): 149-153.

7. Tzschentke B (2007) Attainment of thermoregulation as affected by environmental factors. Poult Sci 86(5): 1025-1036.

8. Calabrese EJ, Baldwin LA, Holland CD (1999) Hormesis: a highly generalizable and reproducible phenomenon with important implications for risk assessment. Risk Anal 19(2): 261-281.

9. Nilsson E, Larsen G, Manikkam M, Guerrero-Bosanga C, Savenkova MI, et al. (2012) Environmentally induced epigenetic transgenerational inheritance of ovarian disease. PLoS One 7(4): e36129.

10. Pang S, Curran SP (2012) Longevity and the long arm of epigenetics: Acquired parental marks influence lifespan across several generations. Bioessays 34(8): 652-654.

\section{Your next submission with Juniper Publishers will reach you the below assets}

- Quality Editorial service

- Swift Peer Review

- Reprints availability

- E-prints Service

- Manuscript Podcast for convenient understanding

- Global attainment for your research

- Manuscript accessibility in different formats

( Pdf, E-pub, Full Text, Audio)

- Unceasing customer service

Track the below URL for one-step submission https://juniperpublishers.com/online-submission.php 